\title{
KEROSENE POISONING IN CHILDREN
}

\author{
BY \\ E. A. CACHIA and F. F. FENECH \\ From St. Luke's Hospital, Malta
}

(RECEIVED FOR PUBLICATION MARCH 3, 1964)

The advisability or otherwise of carrying out routine gastric lavage in cases of kerosene poisoning is still much debated (Olstad and Lord, 1952; Gerarde, 1959; Capel and Gardner, 1960; George, 1960; Ashkenazi and Berman, 1961). The most recent and comprehensive study has been carried out by the American Pediatric Association (Report of the Subcommittee on Accidental Poisoning, 1962). However, further studies are necessary to decide whether gastric lavage should be undertaken (Brit. med.J., 1963). The purpose of our study is to review our cases of kerosene poisoning and to investigate whether omission of gastric lavage in the routine treatment of kerosene poisoning is justified.

\section{Clinical Material}

Between 1948 and 1962, 506 cases were admitted to one of the two paediatric wards of St. Luke's Hospital. An average of 30 cases were seen annually, $78^{\circ}$ obeing between the ages of 1 and 3 years (agreeing with the incidence $83^{\circ}$ o found in a Co-operative study of the American Pediatric Association noted above. The incidence of kerosene poisoning in adults in Malta is not known but it must be low. The age and sex distribution are summarized in Table 1.

TABLE 1

AGE AND SEX DISTRIBUTION OF 506 CASES

\begin{tabular}{|c|c|c|c|c|c|c|c|c|c|c|}
\hline \multirow{2}{*}{ Years } & \multicolumn{10}{|c|}{ Age in Years } \\
\hline & $\overline{1}$ & $\overline{1-2}$ & $\overline{2-3}$ & $\overline{3-4}$ & $\overline{4-5}$ & $5-6$ & $\overline{6-7}$ & $\overline{7-8}$ & $\overline{8-9}$ & $>9$ \\
\hline $1948-1949$ & 7 & 220 & 175 & 54 & 23 & 17 & 5 & 3 & 1 & 1 \\
\hline
\end{tabular}

Sex: male 324: female 182.
The incidence of kerosene poisoning in the various months throughout the years since 1948 is illustrated in Table 2. Nearly half $\left(47^{\circ} \%\right)$ of the cases occurred in the three hot months between June and August. It is reasonable to suggest that during these months the child is liable to be thirsty and to drink the kerosene that is inadvertently left within his reach in mistake for water. It is a common habit in Malta for housewives to keep kerosene in empty wine bottles rather than in cans.

Families in the lower income group contributed $90^{\circ}{ }_{0}$ of the cases. Working-class families in Malta tend to be large, and hence close parental supervision is often lacking.

It was very difficult to estimate the amount of kerosene ingested. In $47^{\circ}$ of the cases, the amount ingested was not known; in $40^{\circ}$ o the parents thought that the amount ingested was about one to two teaspoonfuls, in $10^{\circ}$ o between two teaspoonfuls and one ounce, and in $3^{\circ}$ o one ounce or more. Our experience suggests that children usually ingest only small amounts of kerosene, rarely more than one to two teaspoonfuls.

\section{Clinical Features}

The commonest history is that of a mother who takes her child to the doctor because she found him coughing and flushed near a kerosene bottle, and with his mouth and often his clothes smelling of kerosene. Sometimes the child is referred to hospital a day or two after he ingests the kerosene, when he is brought in feverish, dyspnoeic, and with clinical evidence of pneumonitis. Occasionally the child is in coma. One-third of our cases vomited spontaneously.

TABLE 2

MONTHLY INCIDENCE DUR!NG PERIOD 1948-62

\begin{tabular}{|c|c|c|c|c|c|c|c|c|c|c|c|c|}
\hline Jan. & Feb. & Mar. & Apr. & May & June & July & Aug. & Sept. & Oct. & Nov. & Dec. & Total \\
\hline 22 & 15 & 25 & 36 & 47 & 75 & 94 & 69 & 32 & 43 & 31 & 17 & 506 \\
\hline
\end{tabular}


Pulmonary Complications. The following clinical criteria, fever, dyspnoea, crepitations, and rhonchi, were used in diagnosing pneumonitis. Pulmonary complications occurred in $24^{\circ}$ of the gastric-lavage group and in $22^{\circ}$ of the subsequent 109 cases not having gastric lavage $\left(19^{\circ}{ }_{0}\right.$ in 397 non-gastriclavage cases). The incidence of pulmonary complications in the gastric-lavage group for those who vomited was $26^{\circ}{ }_{0}$, and for those who did not, $22^{\circ}{ }_{0}$. In the first 109 cases of the non-gastric-lavage group, it was $26^{\circ}{ }_{0}$ for those who vomited, and $19^{\circ}{ }_{0}$ for those who did not; for the whole 397 non-gastric-lavage group it was $24^{\circ}$ o and $17^{\circ}$ o for those who did and did not vomit. A chest radiograph was taken in 79 cases, with evidence of pneumonitis in 61 cases and with negative results in 18 . We were often struck by the presence of positive radiological evidence of pneumonitis in the absence of clinical signs and symptoms. Thus in 14 of the radiologically positive cases there was radiological evidence of pneumonitis and yet absence of fever and clinical signs in the chest. In none of the 18 radiologically negative cases was there clinical evidence of pneumonitis. These findings suggest that the true incidence of pneumonitis would have been much higher if all the cases had been submitted to radiological investigation. Radiologically, the lesions were right-sided in 37 cases, left-sided in 11, and bilateral in 13. Olstad and Lord (1952) reported that the lower lobes were the commonest site for the pneumonitis, this was the case in our series also.

Central Nervous System Complications. Central nervous system involvement was assessed by the presence of lethargy, stupor, semi-coma, coma, and convulsions. In the gastric-lavage group, $36^{\circ}$ o were considered to have shown evidence of central nervous system involvement as compared with $23^{\circ}{ }_{0}$ in the non-gastric-lavage group. Lethargy accounted for $93^{\circ}$. of those cases showing central nervous system complications. Coma was found in 5 and convulsions in 2. It was not possible to work out the relation between the amount of kerosene ingested and the degree of involvement of the central nervous

TABLE 3

DURATION OF FEVER

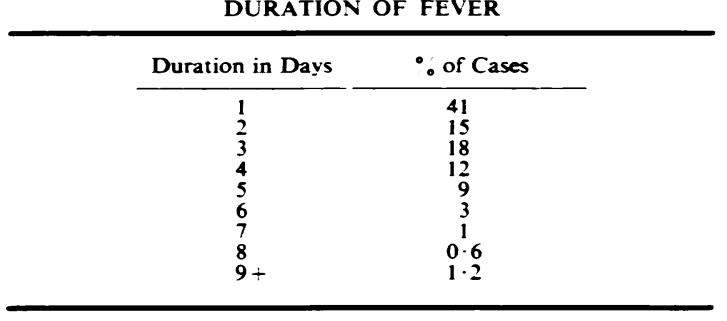

system, as in the majority of cases the amount of kerosene ingested was not known. It is reasonable to assume, however, that the greater the amount ingested, the more severe the degree of central nervous system depression; this is borne out by the American Co-operative study. In our series, the incidence of central nervous system complications was significantly higher in the gastric-lavage group. The general condition of the child often deteriorated temporarily after the upset brought about by the gastric lavage.

Fever. Fever $(100=$ F. $(37 \cdot 8=$ C. $)$ or over $)$ was found in $73^{\circ}$ o of the gastric-lavage cases and in $55^{\circ}{ }_{0}$ of the non-gastric-lavage group. It was very common to find a temperature of 103 or $104=\mathrm{F}$. $\left(39.4\right.$ or $40^{-}$C.) on admission or soon after, and to see it subside to normal within 24 hours. Table 3 shows the duration of the increased temperature in the 298 cases with fever.

Treatment and Hospitalization. Since 1951 we have given up routine gastric lavage in all cases of kerosene poisoning, so that only 109 out of a total of 506 cases were treated thus. Up to 1957, all cases were admitted to hospital, and prophylactic antibiotic therapy in the form of penicillin, or penicillin and streptomycin, or a tetracycline was given routinely. Oxygen and nikethamide were sometimes administered. Since 1958 those cases that were found to be afebrite, alert, and in whom no abnormality was detected, were not admitted into the ward but were sent home, and the parents were instructed to give the required antibiotic, to watch out for fever, and to seek readmission into hospital in the case of regression. During the whole period under review, there was only one death; this was a 1-year-old baby who was comatose on admission and who died 12 hours later. This death occurred in 1948 when gastric lavage was being routinely carried out.

The median duration of hospital stay was $3 \cdot 8$ days for each patient compared to $5 \cdot 5$ days of Olstad and Lord (1952) and 2.3 days of the American Co-operative study (1962); and 54 patients $\left(10 \cdot 6^{\circ}{ }_{0}\right)$ were not admitted. The longest period of stay in hospital was 28 days (Table 4 ).

TABLE 4

DURATION OF STAY IN HOSPITAL

\begin{tabular}{|c|c|c|}
\hline \multirow{2}{*}{$\begin{array}{c}\text { Duration in } \\
\text { Hospital } \\
\text { (days) }\end{array}$} & \multicolumn{2}{|c|}{ Cases } \\
\hline & No. & $\therefore$ \\
\hline $\begin{array}{c}1 \\
2 \\
3 \\
4-5 \\
6-8 \\
9 \div\end{array}$ & $\begin{array}{r}101 \\
93 \\
66 \\
72 \\
66 \\
54\end{array}$ & $\begin{array}{l}20 \\
18 \cdot 4 \\
13 \\
14 \cdot 2 \\
13 \\
10 \cdot 6\end{array}$ \\
\hline
\end{tabular}




\section{Discussion}

The controversial problem in the management of cases of kerosene poisoning is the advisability or otherwise of carrying out gastric lavage and in which patients, if any, it should be done.

It has been established that pneumonitis may follow gastro-intestinal absorption of kerosene. This has been shown experimentally in animals (Deichmann, Kitzmiller, Witherup, and Johansmann, 1944: Ashkenazi and Berman, 1961). Richardson and Pratt-Thomas (1951) ligated the cardia of dogs and injected kerosene directly into the stomach: and from their studies they concluded that a $50 \mathrm{lb} .(23 \mathrm{~kg}$.) child would have to ingest more than a pint $(600 \mathrm{ml}$.) of kerosene to develop a severe pneumonitis. Gerarde (1959) estimated the ratio of the oral to intratracheal $\mathrm{LD}_{50}$ as being approximately $140: 1$. In a later study Gerarde (1963) stated that the tendency of a substance to constitute an aspiration hazard to the lung depended primarily on its physical properties; it is the combination of low viscosity and low surface tension that is responsible for the aspiration hazard of light hydrocarbons such as kerosene.

Olstad and Lord (1952) recommended that gastric lavage should be carried out regardless of the amount ingested. George (1960) put forward similar advice because of the possible toxic properties of the kerosene. In the American Co-operative study (1962) it was found that gastric lavage was not harmful to the patient, but there was no conclusive evidence that it was beneficial; it was also found that the presence of pulmonary complications associated with fever was more closely related to the presence of vomiting and to ingestion of amounts greater than one ounce than to the use or omission of gastric lavage. Gerarde (1959) believes that since the oral toxicity of kerosene is low, the treatment of kerosene poisoning should not include gastric lavage.

Our clinical results are in agreement with Gerarde 's experimental findings, and we believe that there is no place for routine gastric lavage in cases of accidental kerosene poisoning. Gastric lavage would be indicated only if its use would produce better therapeutic results than if it was omitted, whereas our study has shown that no such beneficial effect exists; the incidence of complications being higher in the gastric-lavage group. Gastric lavage should be reserved for those cases where there has been ingestion of large amounts of kerosene. In none of our last 397 cases was there any such indication. Our mortality is $0 \cdot 2^{\circ}{ }_{o}$ compared with $0 \cdot 28^{\circ}{ }_{o}$ in the American Co-operative study; others quote a mortality of $4-10^{\circ}{ }_{o}$ (Blattner, 1951).

\section{Summary}

This paper reviews 506 cases of kerosene poisoning. Gastric lavage was done in 109 cases, but in none since 1951. Complications were more common in the gastric-lavage group; there was no fatality in the 397 cases treated without gastric lavage. Gastric lavage should be reserved for those rare instances when large amounts of kerosene are known to have been ingested.

We should like to thank the Chief Government Medical Officer for permission to publish this paper.

\section{REFERENCES}

Ashkenazi. A. E., and Berman. S. E. (1961). Experimental kerosene poisoning in rats. Pediatrics. 28. 642.

Blattner. R. J. (1951). Kerosene poisoning. J. Pediat.. 39. 391

Brit. med. J. (1963). Annotation. Kerosene (paraffin) poisoning. 1 208.

Capel. E. H.. and Gardner. A. W. (1960). Kerosene (paraffin) poisoning. Lancet, 1, 282.

Deichmann. W. B.. Kitzmiller. K. V.. Witherup S.. and Johansmann. R. (1944). Kerosene intoxication. Ann intern. Med.. 21. 803

George. B. (1960). Kerosene (paraffin) poisoning. Lancet. 1. 826 Gerarde. H. W. (1959). Toxicological studies on hydrocarbons V. Kerosine. Toxicol. appl. Pharmacol. 1. 462

(1963). Toxicological studies on hydrocarbons. IX. The aspiration hazard and toxicity of hydrocarbons and hydrocarbon mixtures. Arch. environm. Hlth, 6, 329.

Olstad. R. B.. and Lord. R. M.. Jr. (1952). Kerosene intoxication. Amer. J. Dis. Child. 83. 446.

Report of the Subcommittce on Accidental Poisoning (1962). Co-operative kerosene poisoning study. Pediatrics, 29, 648

Richardson. J. A.. and Pratt-Thomas. H. R. (1951). Toxic effects of varying doses of kerosene administered by different routes. Amer. J. med. Sci.. 221. 531. 